DOI: https://doi.org/10.14232/actahisp.2021.0.113-119

\title{
PERE CALDERS EN HONGARÈS: ANTAVIANA - CONTES FANTÀSTICS DE LA TERRA I DEL MÉS ENLLÀ
}

\author{
DÓRA BAKUCZ
}

Universitat Católica Pázmány Péter, Budapest

\begin{abstract}
Resum: En la col·lecció Biblioteca Catalana de l'Editorial L'Harmattan al 2021 es publicarà una antologia de Pere Calders compilada expressament per a aquesta edició. L'article és una presentació de l'autor català als lectors hongaresos: després de la descripció general de l'obra de l'escriptor i l'explicació del títol del llibre, es parla de la seva possible comparació amb l'hongarès István Örkény i es presenta una aproximació a l'estil de Calders segons les categories amb les quals es caracteritzen els seus textos en la crítica literària.
\end{abstract}

Paraules clau: Pere Calders, Antaviana, István Örkény, literatura fantàstica, traducció.

Abstract: In the collection Biblioteca Catalana of the Editorial L'Harmattan there will be published in 2021 an anthology by the Catalan storyteller, Pere Calders, compiled specifically for this edition. The paper is a presentation of the Catalan author to Hungarian readers: after the general description of the writer's work and the explanation of the title of the book, there is a possible comparison with the Hungarian István Örkény and an approach to the style of Calders, presented according to the categories we frequently find in literary criticism.

Keywords: Pere Calders, Antaviana, István Örkény, Fantastic, Translation.

\section{Pere Calders i els seus contes: un autor que no es pot prendre seriosament}

Abel un dia es desperta amb una paraula al cap, que va descobrir en els seus somnis: Antaviana, i necessita, amb urgència, trobar-li un significat. Budapest fa olor de aigua timolada amb èter barrejada a l'1 per 100, i en algun lloc de la ciutat hi ha un carrer estret habitat per ninots. Qualsevol dia que tornem del treball podem assabentar-nos que a la nostra casa viu una altra família. Quan anuncien l'arribada de la fi del món, no val la pena fer esperar més la nit de noces. Si per casualitat matem la nostra parella durant una discussió, existeix la possibilitat de vendre'n el cadàver. Els estranys que tanta por ens fan, moltes vegades tenen exactament el mateix aspecte $i$ es comporten igual que nosaltres mateixos. La gent sempre perd coses, hi ha qui perd, per exemple, el braç esquerre. Fins i tot un raspall de roba pot convertir-se en el gos més fidel i obedient del món. Podem llegir aquest tipus d'històries en l'antologia de Pere Calders que es publicarà en la col·lecció Biblioteca Catalana de l'Editorial L'Harmattan al 2021, com a resultat del treball de Montserrat Bayà, que es va encarregar de la selecció dels textos expressament per a l'antologia en hongarès, de Kálmán Faluba, editor de la col·lecció, de 13 traductors hongaresos de diverses generacions, i de l'autora d'aquest article, Dóra Bakucz. El text que ve a continuació és una presentació de l'autor català als lectors hongaresos. 
Pere Calders en hongarès: Antaviana - contes fantàstics de la terra i del més enllà

\section{Antaviana: una paraula a la recerca de significat $i$ un autor a la recerca de públic}

Als Països Catalans quan algú esmenta la paraula Antaviana, tothom pensa immediatament en Pere Calders. Això és sobretot gràcies a l'adaptació d'alguns contes de l'autor que va fer la companyia de teatre Dagoll Dagom als anys 70. L'espectacle va tenir molt d'èxit malgrat que Pere Calders, segons explica ell mateix en una entrevista, va protestar fins a l'últim moment contra la funció, fins a tal punt que va preparar una llista d'arguments de per què no haurien de portar els seus textos als escenaris. Malauradament la llista es va perdre i per tant no podem saber què és el que no li agradava, si el fet que els contes canviessin en posar-los en un context concret i tallar-los perquè funcionessin com a peça teatral, o simplement la idea de transformar les narracions en una obra d'un altre gènere. No obstant això, segons les llegendes del món literari català, quan va veure el resultat en l'assaig general, ja no va protestar més, i va resultar ser una molt bona decisió considerant la reacció tan positiva del públic i dels crítics.

L'any 1984 el crític de teatre Xavier Fàbregas, a propòsit d'una transmissió televisiva de la funció Antaviana de 1978 va dir: "De vez en cuando aparece en el panorama teatral un espectáculo que, al margen de sus méritos intrínsecos, obtiene del público tal respuesta que su éxito se recuerda después, durante décadas, como un hito" (Espinàs, 2010). En un altre lloc va més enllà i defineix la nit de l'estrena com "la nit en què a Catalunya el teatre va fer un gir copernicà” (Dagoll Dagom, 01-09-2021).

Diu això d'una banda perquè després d'un llarg període teatral en què les obres tractaven sobretot problemes socials i conflictes del passat, era una veritable novetat una funció divertida en què les situacions a primera vista semblen quotidianes i conegudes per al públic, però després d'un moment a l'altre, amb un gir inesperat, porten els espectadors a altres dimensions i d'aquesta manera, i també gràcies a la força, dinàmica $\mathrm{i}$ estil del text, els treu de la realitat en la qual viuen. A més, no hem d'oblidar que al 1978 estem pocs anys després de la mort de Franco i que el franquisme significava per a la cultura catalana una repressió i censura que havia causat molt de mal i en aquests anys el teatre català estava a la recerca d'una nova identitat. En aquesta cerca Antaviana de Dagoll Dagom va ser una proposta molt important ja que, com hem esmentat, significava una possibilitat molt diferent del que es veia en els teatres catalans de l'època. D'altra banda, Dagoll Dagom està entre les primeres companyies que feien teatre en català i no en espanyol. Un any després de la publicació de l'article citat, a l'any 1985, la companyia va tornar a representar Antaviana i la notícia va arribar fins i tot a Hongria, com ho testimonia la revista hongaresa Világszínház, especialitzada en teatre (Világszínház, 1985). Aquesta és, doncs, la representació teatral gràcies a la qual els contes de Pere Calders van arribar a ser àmpliament coneguts i populars pel públic. En cercles literaris ja ho eren d'ençà de la publicació del llibre Cròniques de la veritat oculta, el 1955, els crítics literaris aviat van començar a comparar la seva importància i originalitat amb contistes com Jorge Luis Borges, Julio Cortázar o Gabriel García Márquez, però el 


\section{Dóra Bakucz}

gran èxit popular li va arribar sens dubte gràcies a l'interès pels seus textos que desperta la representació de Dagoll Dagom.

Pel que fa al conte que dona títol a l'obra de teatre, Antaviana, és una història en què un nen descobreix aquesta paraula en els seus somnis, i com que no significa res, comença a buscar-li sentit. Gràcies a la popularitat de la versió teatral i també a l'èxit dels contes, l'expressió antaviana va començar a tenir vida pròpia fins al punt que un grup d'escriptors va demanar de forma oficial que incloguessin la paraula en el diccionari de la llengua catalana. Aviat va aparèixer el contra-grup (del qual formava part, entre altres, Quim Monzó, un dels contistes catalans més coneguts de finals del segle XX i començament del XXI, traduït també a l'hongarès, i considerat per molts crítics com una mena d'hereu literari de Pere Calders). L'argument principal dels qui no volien incorporar la paraula al diccionari era que en aquest cas haurien de donar-li un sentit concret fins i tot si aquest sentit concret és justament la falta d'un sentit concret o la multiplicitat de sentits. I amb això privarien la paraula de la seva naturalesa.

No hem triat aquest títol per a l'antologia dels contes de Pere Calders en hongarès només perquè a partir de la publicació del llibre també el lector hongarès pensés en Pere Calders si escolta aquesta paraula, i tampoc per la popular versió teatral, sinó perquè simbolitza perfectament aquella manera, perspectiva de veure la vida que és tan pròpia de l'autor, a la qual tornarem més endavant. El crític abans esmentat, en l'article citat explica també que en els contes de Calders hi ha una cosa en comú: "en la urdimbre de las narracions breves [...] el factor sorpresa es siempre el que rompe la situación, al parecer banal, para llevarnos al otro lado del espejo, a un mundo superreal en el que todo es possible" (Fàbregas, 1984). L'autor, en el text titulat "La revolta del terrat", parla d'aquest fenomen d'aquesta manera: "no se sap mai si la carícia d'una calma servirà per a congriar amb més força una tempesta, o bé quina placidesa protegeix la cara fosca de les agitacions" (Calders, 2008: 36). I en aquests contes n'hi ha de tot: tempesta, placidesa $\mathrm{i}$ agitacions.

\section{La vida de Pere Calders: de Barcelona a Barcelona amb un llarg intermezzo mexicà}

Pere Calders va néixer l'any 1912 a Barcelona i tenia 24 anys quan va esclatar la guerra civil que determinaria la història d'Espanya i de Catalunya al segle XX. Després d'acabar els estudis a l'Escola Superior de Belles Arts, va treballar com a periodista i dibuixant en diferents periòdics, $\mathrm{i}$ de tant en tant publicava també algun conte. Gràcies a la seva qualificació com a dibuixant, en la guerra formà part d'una unitat cartogràfica. El darrer any de la guerra, al 1939, quan ja era clar que els franquistes guanyarien i les represàlies serien molt greus, Calders va fugir a França, i alguns mesos més tard, amb l'ajuda d'una organització que ajudava els refugiats, va continuar cap a Mèxic on va viure més de vint anys, fins al 1962. 
Pere Calders en hongarès: Antaviana - contes fantàstics de la terra i del més enllà

Malgrat les dues dècades que va passar al país llatinoamericà no es va integrar en la cultura local i considerava aquest període com un llarg intermezzo. Una de les explicacions és que a partir del primer moment mantenia una relació estreta amb el cercle d'intel·lectuals catalans exiliats tant a Mèxic com a altres països d'Amèrica Llatina, fins a tal punt que fundaren les seves pròpies revistes, organitzaven programes en català, és a dir, van crear la seva petita Catalunya mexicana (xilena, argentina, etc.) i feien allò que no era possible a la seva pròpia terra: comunicar i crear en la seva llengua materna. Josep Carner, el gran poeta català que després del final de la guerra civil havia de fugir literalment, va passar també una temporada a Mèxic i va intentar posar en contacte els escriptors catalans exiliats amb escriptors mexicans -és gracies a ell que Calders va conèixer, entre d'altres, Juan Rulfo, una de les figures més importants de la literatura llatinoamericana del moment-, però no s'hi va produir cap col-laboració real. D'altra banda, Calders durant l'exili continuava en contacte amb el món cultural català, sobretot a través del seu pare (també escriptor) amb qui intercanviava cartes regularment, al principi en castellà per a no cridar l'atenció. Era el pare qui transcrivia els manuscrits, els preparava per a la publicació i els enviava a revistes que encara funcionaven. El llibre ja esmentat, Cròniques de la veritat oculta, també va ser publicat en la seva absència, el 1955, gràcies a la intercessió del seu pare. Durant els anys a Mèxic va treballar com a dibuixant, il·lustrador i tipògraf, però escrivia també: contes, articles, i fins i tot algunes novel·les.

Quan el seu fill més gran (dels que havien nascut a Mèxic) va complir 15 anys, el 1962, la família va decidir que era hora de tornar a Catalunya. El fet que l'editorial on treballava busqués nous mercats a Europa era un argument més per tornar a Barcelona. El nou començament no era fàcil, ni pel que feia a la feina ni amb la publicació dels seus textos, però finalment va trobar feina a l'Editorial Montaner i Simón i a poc a poc va començar a publicar contes i articles. El problema durant el primer període era que els seus escrits no sempre eren políticament correctes, hi havia revistes que es veien obligades a rebutjar els seus textos per raons polítiques i també li costava trobar el camí cap als lectors. Això podia tenir diverses explicacions: en els anys 60, a Catalunya, ja no hi havia una censura tan rigorosa com abans, però això no significava que la repressió política i cultural hagués acabat. En part és per això que la tendència dominant en la literatura de l'època era l'anomenat realisme històric que, d'una banda, tenia com a objectiu una representació mimètica de la realitat (el millor exemple és la vida atzarosa dels exiliats) i, per l'altre costat, i el que era fins i tot més important, la lluita per l'autonomia, la llengua, i la llibertat en tots els sentits. Quant a la temàtica i la visió, Pere Calders no se'n diferenciava gaire, però en l'estil i la poètica, la literatura que feia sí que era molt peculiar.

És des de la segona meitat dels anys 70, després de la mort de Franco, quan la transició i la democràcia creen un ambient propici per a la mena d'art que representa Pere Calders, que sempre coqueteja amb el fantàstic. Com ja hem vist, és després de l'estrena de l'Antaviana de Dagoll Dagom que els seus textos desperten cada cop més 


\section{Dóra Bakucz}

interès, a partir d'aquest moment els seus llibres es publiquen un rere l'altre, rep una sèrie de premis literaris i avui dia és lectura obligatòria a les escoles catalanes.

\section{Pere Calders és l'Örkény català? Per què no s'ha de prendre aquest autor seriosament?}

"Jo no volia ser absurd ni fantàstic" (Espinàs, 2010), deia Pere Calders diverses vegades quan li preguntaven pel seu estil. Allò que per a la crítica és literatura fantàstica, per a ell és un estil d'expressió que es nodreix del que observa al seu voltant. I per a explicar aquestes observacions, la forma més lliure, segons la seva opinió, és el conte. Va escriure també algunes novel·les i en va començar unes quantes més, però on més còmode se sentia era en el gènere del conte. Quan va ser convidat al popular programa de TV3 Identitats, va explicar que les seves narracions sempre naixien de la realitat que l'envoltava i que, per exemple, un arbre que creixia al centre d'un menjador, o un tigre que apareixia a la cuina, per a ell no eren coses més fantàstiques que una iguana que passejava pel carrer, com ocorria a Mèxic. Però allò que per a ell no era més que una versió personal de la realitat, com un dibuix o una caricatura, als crítics sí que els causava sempre mal de cap. Hi ha una sèrie de treballs sobre l'escriptura de Pere Calders que intenten trobar-li la casella més justa a aquestes històries que parlen de les nostres vides, parteixen de situacions quotidianes, gairebé imperceptiblement fan un gir que sembla la cosa més natural, però al final acaben descrivint una realitat que contradiu les regles de la realitat coneguda per tots nosaltres. És allò que, en un sentit ampli, en diem literatura fantàstica, però els crítics moltes vegades no s'acontenten amb aquesta categoria.

Pel que fa a la descripció i categorització dels textos de Pere Calders, a banda de la categoria de literatura fantàstica trobem amb freqüència adjectius com insòlit, meravellós, irreal, místic, màgic-realista, absurd o grotesc. I és pels últims dos que sorgeix la idea proposada pel màrqueting literari de cridar i considerar Pere Calders l'István Örkény català. Örkény és, sens dubte, una referència coneguda per tots els lectors potencials de llengua hongaresa, però veurem a grans trets què tenen en comú els dos escriptors. Comencem pel més evident: tots dos van néixer el mateix any, i tots dos protestaven contra la categoria literària en la qual els volien encasellar. Örkény no es considerava a si mateix com a escriptor de l'absurd, i Pere Calders, com acabem de veure, protestava tant contra l'absurd com contra la categoria de literatura fantàstica. Els dos van viure una guerra $\mathrm{i}$ fins $\mathrm{i}$ tot es van veure obligats a participar-hi, Örkény en la segona guerra mundial, Calders en la guerra civil espanyola. També en el seu art literari hi ha alguns motius, recursos, marques d'estil en comú, com veurem a continuació. En el cas d'Örkény el grotesc és potser més cridaner, més marcat, aquest mirall que ens posen davant potser distorsiona encara més que en el cas de Calders. Altres elements en comú són la crítica i l'humor, el còmic que en la majoria dels casos (no sempre) transmet el missatge que sí que hi ha esperança fins i tot en el món més boig i cruel. 
Pere Calders en hongarès: Antaviana - contes fantàstics de la terra i del més enllà

Per a veure en què consisteix el fantàstic en el cas de Pere Calders, vegem-ne alguns exemples. Entre les narracions de l'autor trobem contes infantils pròpiament dits, ho assenyala ell mateix al costat del títol: 'conte infantil'. Moltes vegades (per no dir sempre) són aquests textos on apareix el meravellós clàssic, com en el conte "La lluna a casa", que no és cap metàfora ja que es tracta d'una història en què la lluna realment acaba a casa del protagonista. Un altre exemple és "Vorejant la riera", on ens assabentem que la cabanya ruïnosa on entren els personatges per dins és un veritable palau. Però hi ha també elements meravellosos en els relats que no consten com a infantils: necessiten per part del receptor l'acceptació de noves lleis naturals com, per exemple, quan Adam i Eva tenen un fill amb rombes en la pell en el text titulat "El primer Arlequí" o en "Coses de la providència" quan un home, en arribar a casa, es troba en la vida d'una altra persona. I això tampoc no és una metàfora, per descomptat. Tanmateix, hi ha altres casos, quan no cal crear noves lleis naturals ni per al temps de la lectura perquè simplement ocorre una cosa insòlita com en "Catalans pel món" on coneixem un papagai que viu a Birmània i parla català. En "Invasió subtil", un dels contes més coneguts de Calders, tampoc passa res que transgredeixi els límits de l'insòlit, la història de l'home que té la idea fixa que el seu compatriota amb qui comparteix taula en el restaurant de l'hotel és un japonès, probablement se situa entre la ironia i l'absurd. La majoria dels textos, com acostuma a passar, no correspon perfectament a una categoria teòrica concreta, aquests conceptes o categories serveixen simplement per a acostar-nos d'alguna manera a l'estil del nostre autor. Seguint aquesta idea i amb l'ajuda de les categories esmentades podem dir que entre els contes de Calders hi ha l'insòlit que tendeix a l'absurd, com en "La revolta del terrat", en què coneixem la història d'una comunitat de veïns des del moment de mudar-se a l'edifici fins que esclata una veritable guerra entre ells (una altra vegada literalment), insòlit que tendeix a la ciència-ficció com el cas del professor Daimis en "La meva estada al centre de la Terra", que descobreix una pintura que amb una sola gota és capaç de pintar en vermell tota l'aigua de la Mar Mediterrània. Però si busquem un text que sigui un cas més clar de ciència-ficció, podem esmentar "Tecnologia al galop" on un home recorre als serveis d'una empresa que es dedica a fabricar dones-robot.

En l'enumeració de categories que podem trobar en les descripcions de l'estil de Calders hem esmentat el realisme màgic també, del que el primer autor que ens ve al cap és el colombià García Márquez, i narracions en les quals els esdeveniments contats de manera realista, que funcionen segons la lògica racional, es barregen amb elements màgics d'una forma natural. Seria lògic pensar que Calders, durant els anys d'exili a Mèxic, hagués contactat amb el món i les modes literaris llatinoamericans de l'època. En els períodes més durs fins i tot ell mateix es queixava que ja havia vist en la seva vida més indis que pescadors mediterranis, però potser justament per la seva fidelitat a la llengua, cultura i costums catalans el realisme màgic, tal com el coneixem de la ploma d'escriptors hispanoamericans no tenia una influència directa i clara en l'escriptura del nostre autor. 


\section{Dóra Bakucz}

No obstant això, cal admetre que sí que hi ha components màgics en les seves narracions, i apareix també el fenomen -molt característic del realisme màgic- que els personatges accepten els successos irracionals amb una naturalitat sorprenent per al lector, com per exemple quan en el conte "Assaig general" anuncien la fi del món o en "Demà a les tres de la matinada" a ningú no li estranya que un familiar s'hagi mudat a la Lluna.

I aquí arribem a la categoria del grotesc, és a dir quan dues qualitats estètiques oposades són presents alhora en un text, i que és el que més caracteritza l'estil de l’hongarès István Örkény i per tant pot ser un altre punt (aquesta vegada intraliterari) en comú. Pensem, per exemple, en "Vinc per donar fe" on una família sacrifica una tia per por dels vampirs, o en "Estudi per correu" on el resultat d'un gran amor i la gran passió per la taxidèrmia produeixen un efecte morbós, conseqüència del grotesc. Podríem continuar enumerant els exemples de les diverses formes del fantàstic, però potser aquests exemples ja poden servir per a veure com de multifacètic és el món fantàstic de Pere Calders, malgrat que ell protestés tant contra aquesta expressió.

L'any 2000 es va organitzar una exposició de gran volada sobre la vida i obra de Pere Calders al centre cultural i científic CCCB de Barcelona, i se'n va publicar un àlbum en el qual el curador de l'exposició, Joan Melcion va escriure: "En l'univers caldersià, la realitat i la seva representació sovint es confonen. Potser és per fer-nos adonar que també tots nosaltres caiem massa sovint en aquesta confusió, substituint temps per rellotges, màgia per jocs de mà" (Melcion, 2000: 41).

\section{Referències bibliogràfiques}

Antaviana. Presentació. Dagoll Dagom, Companyia de teatre. Disponible a: https://www.dagolldagom.com/ca/antaviana-1978. Data de consulta: 01-09-2021.

Calders, Pere (2021). Antaviana. Fantasztikus elbeszélések Földön innen, Földön túl. Budapest: L'Harmattan.

Calders, Pere (2008). Tots els contes. Barcelona: Labutxaca.

Espinàs, Josep Maria (2010). Identitats. Pere Calders. TV3, 21 de 01 de 2010. Disponible a: https://www.ccma.cat/tv3/alacarta/identitats/pere-calders/video/2419659/. Data de consulta: 01-09-2021.

Fàbregas, Xavier (1984). “Antaviana”, un enorme éxito del teatro catalán, hoy en TVE. La Vanguardia, Edición del martes, 21 febrero, 1984. 66.

Körkép. Spanyolország. Világszínház, 1 de maig de 1985. 4.

Melcion, Joan (2000). L'univers literari de Pere Calders. Dins: Palà, Marina (coord.) Calders. Els miralls de la ficció. Barcelona: Centre de Cultura Contemporània de Barcelona / Institut d'Edicions de la Diputació de Barcelona. 39-145. 